\title{
IMPLANTAÇÃO DE INOVAÇÕES A PARTIR DA INTERAÇÃO ENTRE FIRMAS: ESTUDO DE CASO DO ARRANJO PRODUTIVO DE MÓVEIS DO AGRESTE ALAGOANO
}

\author{
Niedja Figueiredo Dantas
}

\begin{abstract}
Resumo - Esta pesquisa tem como objetivo identificar no Arranjo Produtivo Local Moveleiro do Agreste do Estado de Alagoas os desafios para a Institucionalização da implantação de inovações, considerando os aspectos de novos produtos, novos processos, e novas tecnologias que podem ser utilizadas no APL estudado. A metodologia foi qualitativa, por meio da aplicação de 15 entrevistas com proprietários e/ou gerentes das firmas que integram o APL estudado. As principais conclusões verificadas foram: 1) É baixa a capacidade de inovação do APL Moveleiro do Agreste do Estado de Alagoas; 2) AsInstituições de Ensino e Pesquisa, voltadas à Ciência e Tecnologia, tem começado a contribuir através de pesquisas, de forma ainda tímida; 3) O nível de interação entre os atores que integram o APL é baixo.
\end{abstract}

PALAVRAS CHAVE: Arranjo Produtivo de Móveis; Inovações; Agreste Alagoano.

\section{IMPLANTATION OF INNOVATIONS FROM THE INTERACTION BETWEEN SIGNATURES: CASE STUDY OF THE PRODUCTIVE ARRANGEMENT OF THE ALAGOAN AGRES}

\begin{abstract}
This research aims to identify the Productive Arrangement Furniture Location Agreste Alagoas State challenges for the Institutionalization of implementation of innovations, considering the aspects of new products, new processes, new materials and new technologies that can be used in industry furniture (wood, upholstered, stainless steel, marble and granite). The methodology was qualitative, by applying 15 interviews with owners and / or managers. discourse analysis and document analysis was performed. The main findings were observed: It lowers Moveleiro APL innovativeness of Agreste Alagoas State. The interviews with the furniture manufacturers showed that these institutions Education and Research, focused on Science and Technology, has begun to contribute through research, even timidly. It was not seen any industrial or R \& D laboratory in any of the companies of the APL Moveleiro do Agreste.
\end{abstract}

Keywords: Furniture Productive Arrangement - Innovations -AgresteAlagoano

\section{INTRODUÇÃO}

Num ambiente de alta competitividade setorial,com concorrência global e crise econômica a capacidade de inovação das firmas é fundamental, seja de produtos ou processos. Considerando o estudo da capacidade de promover inovação das empresas participantes de um determinado Arranjo Produtivo Local- APL neste caso ainda é mais crucial, haja vista que a inovação e o aprendizado coletivo são princípios sob os quais os APL's deverão estar alicerçados.

O aprendizado coletivo interativo nos APL's está relacionado a transmissão de conhecimentos e a ampliação da capacidade tecnológica e inovativa das firmas. Passa também pela implementação de ações que estimulem as empresas e outros locais a interagirem. Passa também pela implementação de ações que estimulem as empresas e outros locais a interagirem e pela capacitação das pequenas e médias empresas e melhorem nas instituiçõesde apoio.

Desta forma este artigo procura articular a discussão sobrea geração de inovação a partir dos conceitos de Arranjos Produtivos Locais - APL e analisar especificamente o APL de móveis

REVISTA ECONOMIA POLÍTICA DO DESENVOLVIMENTO $\quad$ Maceió - AL $\quad$ V.4 N.6. $\quad$ DEZEMBRO/2017 P.80-99 Página-80


do Agreste de Alagoas, utilizando para isso um referencial analisado baseado no conceito de APL's e os vínculos e interações de cooperação entre firmas, de modo que por meio desses vínculos a possiblidade do processo a introdução de inovações de produtos, processos torna- se real, gerando maior competitividade para as empresas que fazem parte do Arranjo.

Nessa perspectiva, em investigação tem como questão a norteadora a reflexão: quais aspectos tem dificultado a implementação de inovaçõesnas empresas integrantes do APL? A hipótese prevista sugere que problemas relacionados ainteração entre os atores das firmas integrantes do APL e entidades parceiras emé baixa etem dificultado o desempenho inovativo das empresas que fazem parte do APL estudado.

A análise realizada desdobra - se a cinco seções.

A primeira seção apresenta uma possibilidade de compreensão acerca da política de Arranjos Produtivos como estratégia inserida na política industrial, visando o desenvolvimento dos territórios produtivos.

A segunda seção promove uma reflexão sobre Inovação.

A terceira seção propõe uma reflexão entreinteração e cooperação entre os atores de um Território Produtivo do APL.

A quarta seção apresenta uma caracterização do Arranjo Produtivo de Móveis do Agreste Alagoano.

A quinta seção aborda a metodologia utilizada na pesquisa.

A sexta seção apresenta e discute os resultados de acordo com os dados coletados.

A última seção conclui.

\section{Seção 1: Entendendo a Política de Arranjos Produtivos como política de DESENVOLVIMENTO PRODUTIVO}

Ao longo do século $\mathrm{XX}$, ficou evidente que o desenvolvimento não é um processo mecânico e rígido, fruto da raça ou clima, da abundância de recursos naturais ou de um posicionamento geográfico, mas sim de um conjunto de iniciativas, resultantesda adequada leitura das tendências futuras. Os paísesque realizaram os maiores avanços, tanto na vanguarda histórica quanto os que saíram dos diversos níveis de retaguarda, os alcançaram por uma consistente articulação de políticas públicas voltadas para o desenvolvimento produtivo e dos circuitos de distribuição, que juntamente com a iniciativa privada os conduziram a níveis de competitividade global e inserção no mercado externo. Encontramos exemplos desseprocesso na 
explosão industrial dos tigres asiáticos, no gigantes salto da China, que já atingiu níveis de crescimento no PIB da ordem de 10\%a.a.

Da mesma forma, se sabe das insuficiências do sistema econômico capitalista puro de resolver questões que vão além do mercado. Nesse campo, estão os problemas sociais, e os problemas ambientais dentro do contexto histórico presente. E foi nesse vácuo que a ideia de desenvolvimento localfoi tomando força não como uma nova forma de sistema político, mas como uma forma de pensar e construir o processo de desenvolvimento dos municípios.

Nogoverno Luiz Inácio Lula da Silva debateu -se a importância das políticas industriais para uma retomada do processo de desenvolvimento. $\mathrm{O}$ Ministério da Indústria, Desenvolvimento e Comércio Exterior capitaneou o debate entre os diversos atores institucionais e empresários, e estimulou as discussões acerca da política industrial como um dos eixos centrais daestratégia de desenvolvimento do Brasi (no Plano Plurianual de Ações do Governo Federal (PPA) para o período 2004- 2006. O atual governoTemmer (2016) ainda inclui no PPA a política de o desenvolvimento de Arranjos Produtivos Locais (APL's) como uma das estratégias de política industrial. O SEBRAE está trabalhando com os Arranjos Produtivos com cerca de 230 APL's em todo o Brasil.

Os Arranjos Produtivos Locais, com produtos tradicionais, de base agrícola, de alta tecnologia, de Turismoou industrial, poderiam ser trabalhados no sentido de avançar na superação de deficiências que geram subdesenvolvimento de certos municípios brasileiros, poderia proporcionar o aprofundamento das formas de interação mutuamente benéficas entre os empresários e na geração de um clima de aprendizado coletivo voltado para a apropriação de tecnologias novas e do conhecimento mais amplo do mercado nacional, de forma a refletir mais decisivamente na inserção competitiva.

Considerados os diferentes estágios de desenvolvimento, os APL's estão presentes em todo o território nacional, nas grandes, médias e até mesmo em pequenas cidades. Dentro de suas comunidades, envolvem um grande número de pessoas, comproporção significativa da população economicamente ativa. Polarizam outras cidades, gerando uma rede integrada com forte potencial de crescimento. Atacar seus pontos fracos, fomentar seus pontos positivos, explorar as oportunidades mercadológicas que se descortinam para eles significará implantar uma política de desenvolvimento interno, autônomo, baseado na capacidade de iniciativa dos atores locais, como também com o apoio de entidades parceiras entre as quaispodemos citar Banco do Nordeste, o SEBRAE e o próprio estado passando a atuar de forma organizada e complementar, visando o fortalecimento das empresas de pequeno porte dos Estados.

Arranjos Produtivos Locais são aglomerações de empresas e de empreendedores localizados em um mesmo território, que apresentam especialização produtiva e mantêm algum 
vínculo de articulação, interação, cooperação e aprendizagem entre si e com outros atores locais tais como governo, associações empresariais, instituições de crédito, ensino e pesquisa. (Petrochi, 2015). O Arranjo Produtivo Local pressupõe uma identificação coletiva de diferentes municípios envolvendo características culturais, econômicas, ambientais e sociais que significam a base para a união e cooperação dos atores envolvidos, formando uma rede complexa de relações sociais com a parceria e o compromisso social.

\footnotetext{
"Um Arranjo Produtivo Local - APL - é caracterizado pela existência de um agrupamento significativo de empresas que atuam em torno de uma atividade produtiva principal. Para isso, é preciso considerar a dinâmica do território em que essas empresas estão inseridas, tendo em vista o número de postos de trabalho, faturamento, mercado, potencial de crescimento, diversificação, entre outros aspectos." (Caporali, 2004)
}

A política de Arranjos Produtivos Locais foi abraçada pelo Estado de Alagoas como possibilidade de reverter o quadro em que se encontra a sua economia. Neste contexto a análise desenvolvida a seguir constitui uma tentativa de avaliar, a partir da reflexão teórica e da aplicação de entrevistas,quais os aspectos que tem dificultado a implementação de inovações das empresas integrantes do APL.

\section{Seção 2: Reflexão sobre Inovação:}

A inovação é produto do conhecimento que, numa economia global, pode ser considerada a maior fonte de vantagem competitiva da empresa. Segundo Han, Kim e Srisvatava (2008) a empresa orientada para o marketing é aquela que busca o novo e o diferente como resposta à dinâmica do mercado, sugerindo que, para que haja inovação, faz-se necessário que os dirigentes vejam o processo de mudança e inovação como algo saudável. Estes autores analisam que "a gestão da inovação é a mais vital das tarefas da gerência”. Organização inovadora, eles argumentam, é o resultado da gerência que é estratégica e da liderança que tem visão. A inovação pode se tornar um "modo de vida" organizacional através da habilidosa gestão de pessoas, estruturas, valores e aprendizado. Segundo estes autores, as organizações inovadoras são altamente eficientes em aprender, autocríticas e compromissadas com o aperfeiçoamento contínuo. Elas são também eficientes em sintetizar conhecimento de mercado com desenvolvimento de produtos e serviços. Estes dois autores abordam acerca da importância da Inovação, observando que as organizações devem buscar o novo e o diferente, a partir do conhecimento do mercado.

No tocante a análise da inovação nos Arranjos Produtivos Locais, as empresas integrantes, devem estabelecer a promoção de inovação a partir da troca de conhecimento, interação baseada em vínculos fortes visando a melhoria contínua, desenvolvimento de novos produtos ou processos de todas as firmas do APL. 
Cassiolatoe Lastres (2015) já afirmaram que "Arranjos Produtivos Inovadores são aqueles cuja interdependência e articulação consistentes resultam em interação, cooperação e aprendizagem, possibilitando inovações de produtos, processos e formatos organizacionais e gerando maior competitividade empresaria e capacitação social” .

Segundo DRUCKER ${ }^{1}$, organizações inovadoras são aquelas quepromovem inovação sistemática, consistindo na busca, intencional e organizada, de mudanças e na análise das oportunidades que tais mudanças poderiam oferecer para inovações econômicas e sociais. Ele prossegue identificando sete fontes, que devem ser buscadas como sinais e fontes de uma chance para inovar. Quatro dessas fontes estão dentro da empresa, ou do setor no qual opera: (1)O sucesso ou fracasso inesperado; (2) a incongruência (discrepância entre a realidade como ela é e como é suposta ser); (3) a inovação baseada em necessidade do processo; (4) mudanças nas estruturas do setor em que a empresa está inserida, que apanham as pessoas de surpresa. As outras três fontes envolvem mudanças fora da empresa ou setor a que pertence, isto é são: (5) demográficas; (6) mudanças de gostos, percepções e significados; e por último, (7) a fonte de inovação é sempre o inesperado, especialmente o sucesso inesperado.

Ao se analisar a inovação no âmbito dos APL's tem - se que:

"Arranjos Produtivos Inovadores são aqueles cuja interdependência earticulação consistentes resultam em interação, cooperação e aprendizagem, possibilitando inovações de produtos, processos e formatos organizacionais e gerando maior competitividade empresaria e capacitação social". (Cassiolato e Lastres, 2015) já afirmaram que "Neste contexto a próxima seção reflete sobre como as interações e cooperação entre os integrantes do Território Produtivo de um Arranjo Produtivo Local."

\section{Seção 3: Interação e cooperação entre os atores no Território Produtivo de umArranjo Produtivo Local}

A noção de território é fundamental para a atuação em APLs. No entanto, a ideia de território não se resume apenas à sua dimensão material ou concreta. Território é um campo de forças, uma teia ou rede de relações sociais que se projetam em um determinado espaço. Nesse sentido, o APL também é um território onde a dimensão constitutiva é econômica por definição, apesar de não se restringir a ela.O ponto de vista que ampara as ações implementadoras de APLs é a de que desenvolvimento não é sinônimo de crescimento econômico. Existe um desafio muito maior, que é o de aprofundar a democracia e erradicar a pobreza, combinando crescimento econômico com redução da desigualdade. A manutenção da estabilidade

\footnotetext{
${ }^{1}$ DRUCKER, Peter. Administração para o Futuro: Os anos 90 e a virada do século. 6 a ed. São Paulo: Pioneira, 1996. 
macroeconômica é condição necessária, mas não suficiente, para que essas transformações possam se dar. É preciso ir além, evitando reeditar modelos do passado, nos quais desenvolvimento se reduziu ao crescimento da acumulação e concentração do capital - em detrimento do bem-estar do conjunto da população, do equilíbrio das contas externas, do poder de compra da moeda, do meio ambiente e da própria democracia. Não adianta, pois, investir no desenvolvimento de iniciativas empresariais sem levar em conta outros pressupostos do desenvolvimento, tais como, segundo Petrochi (2005):

- "o capital humano (os conhecimentos, habilidades e competências da população local, as condições e a qualidade de vida);

- o capital social (os níveis de confiança, cooperação, reciprocidade, organização social e empoderamento da população local);

- a governança (a capacidade gerencial do governo e os níveis de participação e controle social);e

- o uso sustentável do capital natural.”

Quaisquer empresas, por mais dinâmicas e eficientes que sejam, terão mais oportunidades de progredir sustentavelmente quando as condições sociais, culturais, ambientais, físicoterritoriais e político-institucionais forem adequadas. Nessa linha de pensamento verifica-se a convergência de pelo menos duas importantes correntes do pensamento contemporâneo:

\footnotetext{
"por um lado, a que enfatiza a noção de capital social como um conjunto de recursos capazes de promover a melhor utilização dos ativos econômicos pelos indivíduos e pelas empresas; por outro, a que privilegia a dimensão territorial do desenvolvimento e que insiste na ideia de que a competitividade é um atributo do ambiente, antes mesmo de ser um trunfo de cada firma" (Caporali, 2004)."
}

Se constituídos como unidades isoladas, os pequenos negócios terminam por espelhar a forma de funcionamento de grandes empresas, porém sem suas principais vantagens:

- a capacidade de gerar economias de escala;

- de investir em inovação produtiva e gerencial; e

- de contar com profissionais qualificados.

Torna-se então necessário o estabelecimento de novas formas de organização e de ação junto aos pequenos negócios, de forma a superar as deficiências oriundas do porte e do isolamento.

\footnotetext{
"A organização das empresas em arranjos constitui-se em importante fonte geradora de vantagens competitivas duradouras, principalmente quando estas são construídas a partir do enraizamento de capacidades produtivas e inovativas. No entanto, nem todas as aglomerações indicam esse caminho. Partindo do pressuposto de que há um conjunto de variáveis-chaves que, podem ser mobilizadas por redes locais de empresários e outros atores, o APL possibilita transformar a proximidade espacial das empresas numa melhor inserção competitiva de desenvolvimentista sustentável no mercado.” (Sebrae, 2016)
} 
Nesse sentido as potencialidades, vocações e oportunidades, as vantagens comparativas e competitivas de cada arranjo é que orientarão a mobilização das redes locais na busca de um projeto de desenvolvimento que resulte no aumento, sustentável, da competitividade das empresas.

Como forma de promover a inclusão social pela via do empreendedorismo, aqueles territórios que apresentem baixa densidade empresarial, baixa especialização produtiva e baixo dinamismo econômico e social, também são territórios estratégicos para implementação de APLs. Nestes casos, o objetivo principal será o incremento do protagonismo local, ou seja, a constituição e o fortalecimento das redes de atores locais capazes de liderar o processo de mudanças. Trata-se, portanto, de implementar ações que busquem induzir ou promover a emergência de atores sociais aptos a protagonizarem as mudanças políticas, econômicas e sociais que vão deflagrar um processo de desenvolvimento endógeno e sustentável, integrado aos eixos dinâmicos da economia.

Destarte, o Arranjo Produtivo Local compreende um recorte do espaço geográfico que possua sinais de identidade coletiva, devendo manter ou ter a capacidade de promover uma convergência em termos de expectativas de desenvolvimento, estabelecendo parcerias e compromissos para manter e especializar os investimentos de cada um dos atores no próprio território, e promover ou ser passível de uma integração econômica e social no âmbito local.

O APL promove a competitividade e a sustentabilidade dos micro e pequenos negócios, estimulando processos locais de desenvolvimento. Porém, qualquer ação nesse sentido deve permitir a conexão do arranjo com os mercados, a sustentabilidade por meio de um padrão de organização que se mantenha ao longo do tempo, a promoção de um ambiente de inclusão de micro e pequenos negócios em um mercado com distribuição de riquezas, e a elevação do capital social por meio da promoção e a cooperação entre os atores do território.

Sendo assim, para se pensar em inovações nos Arranjos Produtivos Locais desenvolvimento com sustentabilidade é preciso pensar no protagonismodos atores que integram o APL de Móveis do Agreste Alagoano, a integração com outros atores, a mobilização de recursos públicos e privados aportados por agentes de cada projeto, e a atração de recursos públicos ou privados complementares aos aportados. Até que ponto isto acontece no Arranjo Produtivos doe Móveis no Agreste?

Essa reflexão será analisada na próxima seção.

\section{Seção 4: Caracterização do Arranjo Produtivo de Móveis do Agreste Alagoano}

No caso do Arranjo Produtivo Local (APL) de Móveis do Agreste Alagoano, que é o objeto desta reflexão, este atua na estruturação do setor moveleiro nos municípios de Arapiraca e Palmeira dos Índios. Este APL atua na fabricação de móveis de estofados, de madeiras, \begin{tabular}{llllll}
\hline REVISTA ECONOMIA POLÍTICA DO DESENVOLVIMENTO & Maceió - AL & V.4 N.6. & DEZEMBRO/2017 & P.80-99 & Página-86
\end{tabular} 
mármore/ granito e metálicos (ferro, aço e inox). Atua nestes municípios como atividade predominante, sendo acompanhada de outras atividades de importância para o agreste tais como: vestuário, produção e beneficiamento de fumo, calçados, transporte, horticultura, criação de animais, fruticultura, plástico, comércio varejista e outras.

A atividade moveleira no Agreste Alagoano, mas especificamente nas cidades de Palmeira dos Índios e Arapiraca, tem mais de 50 anos de existência, sendo que no início esta atividade era exercida por um número reduzido de empreendedores que ocupavam, na maioria, um número igual ou inferior a 10 funcionários. Estes, através dos anos, deixaram de ser funcionários para abrir uma nova empresa, ou seja, o próprio negócio, fato este que deu origem a um grande número de empreendimentos, presente no território de Móveis do Agreste Alagoano. Em junho de 2015, o número de empreendimentos formais e informais é de 268 pequenas movelarias, contudo para fins desta pesquisa será considerado o número de 75 empresas de móveis, que são as que participam de forma mais efetiva nas ações desenvolvidas no APL. (dados do relatório do SEBRAE, 2015), empregando aproximadamente 2.500 pessoas diretamente na atividade, que são treinados nos próprios estabelecimentos Alguns empreendimentos surgiram da fragmentação familiar onde filhos, que deixavam o ambiente familiar, montavam novas unidades, em geral não vinculadas entre si. Pequena quantidade desses negócios surgiu de empreendedores que nunca tinham trabalhado com a atividade e nem receberam capacitação técnica, mas identificaram a produção de móveis como um meio de sobrevivência.

O faturamento das empresas do APL de móveis do Agreste Alagoano em 2015 foi de aproximadamente $\mathrm{R} \$ 180.000,00$ (cem e oitenta mil reais no ano), considerando as vendas para o mercado estadual das 75 empresas (observando que existem ainda em torno de 150 empresas que não informam os dados, nem participam das ações do APL moveleiro). As empresas deste APL fazem parte do segmento da indústria e comércio, especificamente da fabricação e reforma de móveis. Grande parte dos móveis produzidos no Agreste Alagoanosão móveis sob medida, vendidos diretamente aos consumidores, através do trabalho de arquitetos ou negociação direta com os clientes, a lojistas e nas próprias lojas.

De acordo com as entrevistas realizadas verificou-se que a grande maioria dos empresários (90\%) comercializam seus produtos no próprio Estado de Alagoas, (10) \% também comercializam para outros Estados da federação. Para estes que estão distribuindo seus produtos no mercado nacional e ao mercado externo as dificuldades que têm enfrentado estão relacionadas à: acesso ao consumidor final; acesso aos canais de comunicação e distribuição; atendimento das especificações solicitadas pelo importador; cumprimento dos prazos de entrega especificados; promoção dos produtos e fixação de marca; redução na quantidade solicitada tamanho dos pedidos; burocracia alfandegária e tributária; custos de manuseio; embalagem e armazenagem; custos portuários; do transporte interno e do frete internacional; outros. 
Segundo informes dos empresários que estão produzindo e comercializando os móveis no mercado estadual as dificuldades enfrentadas são: transportes, concorrência de grandes empresas, formas e facilidades de pagamentos oferecidas por empresa de maior porte; falta de mão de obra disponível para aumento de demanda; alto custo de frete interno para vendas para regiões distantes; falta de divulgação sobre a qualidade dos móveis da região.

O desenvolvimento com interesse associativo é bastante comum no grupo dos marceneiros do Arranjo Produtivo de Móveis do Agreste do Estado de Alagoas, onde a preparação para a compra conjunta, utilização de espaço coletivo para desenvolvimento das empresas e negociação com parceiros, fornecedores e instituições estratégicas utilizadas pelos empresários de forma conjunta no intuito de aumentarem a competitividade de suas empresas. $\mathrm{Na}$ associação e sindicato do setor são comuns a interação e cooperação com os empresários existindo caso da associação abrir espaço para convênios e benefícios de interesse dos empresários e dos seus funcionários, como também na busca de negociação que melhor anseie aos interesses do setor.

As empresas em sua maioria são de pequeno porte, não possuindo grande área para de instalação. Em média a área instalada gira em torno de 400 m2, porcada empresa.

Os fornecedores dos insumos (madeira, ferro, aço, tecido, espuma) estão localizados no Estado de Alagoas (Arapiraca, Palmeira dos Índios e Maceió) principais centros fornecedores de matéria prima do APL. Os problemas relacionados a atividade dizem respeito ao uso de madeira nativa, custo de aquisição de matéria prima elevado.

A terceirização é um tipo de serviço ainda não utilizado pelas empresas do APL sendo todas as etapas da atividade relacionadas pelas próprias empresas.

\section{Seção 5: Metodologia da Pesquisa}

O levantamento bibliográfico foi utilizado durante todo o âmbito da pesquisa, especificamente sobre Inovação e Arranjo Produtivo Local, permitindo com que se possa refletir sobre a aplicabilidade destas referências teóricos no caso do APL Moveleiro do Agreste Alagoano.

Foram realizadas 15 (quinze) entrevistas estruturadas junto aos gestores das empresas que fazem parte do APLMoveleiro do Agreste Alagoano, com o intuito de avaliar se o ambiente no APL moveleiro do Agreste Alagoano é propício a inovação, como também verificar os desafios que existem para a promoção da capacidade de inovação nas empresas integrantes deste APL. A entrevista foi estruturada a partir das seguintes variáveis: (A) Capacidade de Inovação; (B)Formas de Interação entre os Agentes Locais; (C) Fontes de Financiamento utilizada pela empresa; (D) Meio de Transporte Utilizado na distribuição do produto; (E) Inovação Tecnológica implantada nos último 5 anos; (E) Qualificação dos funcionários 
Também foram utilizados documentos do APL Moveleiro do Agreste de Alagoas, para confrontação dos dados colhidos nas entrevistas, bem como complementação de informações.

Para compreender os processos de institucionalização da inovação existente no território do APL, optamos pela adoção de procedimentos de caráter qualitativo para a pesquisa de campo. Neste caso, abrindo mão do poder de generalidade das técnicas quantitativas, procuramos destrinchar algumas relações presentes modos de reprodução social da institucionalização da inovação, utilizando informações obtidas por meio de coleta de dados orais, entrevistas semi-estruturadas e observações de campo. Desta feita, a precisão da quantidade de informações foi aqui substituída pela seletividade dos atores envolvidos na teia de relações que dinamizam a conformação territorial. Os informantes foram selecionados a partir dos critérios de amostragem por conveniência. Esta técnica nos permitiu compor um universo amostral baseado na densidade informacional dos atores locais, ou seja, no tipo de informação que estes poderiam fornecer diante dos propósitos da pesquisa.

A amostra foi composta de 15 gestores informantes, distribuídos, pertencentes a 15 empresas instaladas no Município de Arapiraca do APL Moveleiro do Agreste do Estado de Alagoas.

A seleção das 15 empresas deu-se mediante escolha por conveniência, pelo grande número de empresas que fazem parte do APL e de acordo com o objetivo da pesquisa, que é identificar se existe no território do APL um ambiente propício à inovação. Trabalhamos com o modelo de entrevistas semi-estruturada, a qual constitui de perguntas definidas, mas abertas, que ao mesmo tempo permita-nos a introdução de novas questões visando a acompanhar o desenvolvimento ou o aprofundamento do discurso do informante. Por outro lado, o informante, seguindo espontaneamente a linha de seu pensamento e de suas experiências dentro do foco principal colocado pelo investigador, começa a participar na elaboração do conteúdo da pesquisa. Essa flexibilidade, segundo nosso entendimento, possibilitou-nos, entre outras coisas: 1) explorar o universo cultural próprio dos indivíduos em referência às capacidade de verbalizações do grupo ao qual pertence, sem comparação com outros grupos obter do entrevistado os aspectos mais relevantes de determinado problema.

A entrevista semi-estruturada organizada por tópicos temáticos possibilitou-nos, como salientamos, o desenvolvimento de questões espontaneamente introduzidas ou sugeridas pelos informantes, além de respostas às questões estruturadas, ou seja, aquelas apresentadas ao sujeito da mesma forma. Nas entrevistas buscamos desde a caracterização até o aprofundamento dos aspectos vinculados à problemática ambiente propício ao desenvolvimento de inovações, detendo-nos nas motivações, causas, considerações, motivações, etc.

No tocante às transcrições dos relatos orais, procuramos tornar visíveis ao leitor o queQueiroz (2007) chama de espontaneidade do relato, ou seja, as manifestações não 
linguísticas do relator, que decorrem de sua própria reflexão, sem influências alheias, como por exemplo as do entrevistador. Deste modo, as citações orais presentes no texto também indicarão eventuais comportamentais espontâneos manifestados pelos informantes quando da coleta de seu relato.

Buscamos evitar a influência de terceiros na relação entrevistador - entrevistado, procuramos, primeiro, não reproduzir na mesma tais mecanismos, e, segundo, estimular o exercício da autonomia pelo menos no que se refere à expressão de ideias, ponto de vista, sentimentos, entendimento acerca da Política de Arranjos Produtivos Locais; opinião em relação a possibilidade dessa política diminuir a pobreza no Estado de Alagoas; e seus sentimentos e opiniões em relação a desigualdade social no Estado.

Mapa de Alagoas com a Localização dos Municípios de Arapiraca e Palmeira dos Índios

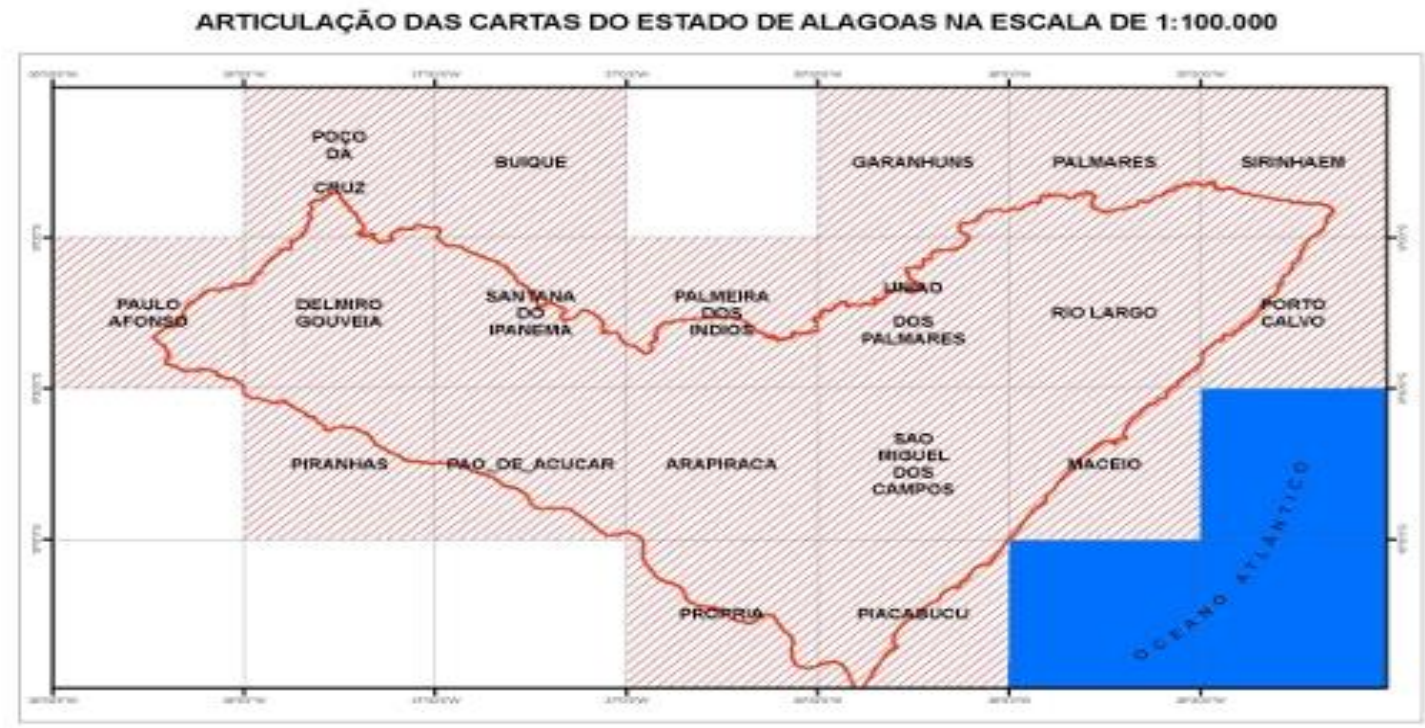

\section{Seção 6: Discussão dos Resultados}

O processo de Institucionalização das Inovações no território do Arranjo Produtivo de Móveis do Agreste do Estado de Alagoas foi o objetivo desta pesquisa, sob a perspectiva de nove categorias analíticas: 1) Capacidade de Inovação;

(2)Formas de Interação entre os Agentes Locais;

(3) Fontes de Financiamentos, utilizada pela empresa;

(4) Meio de Transporte Utilizado na distribuição do produto;

(5) Inovação Tecnológica implantada nos último 5 anos;

(6) Qualificação dos funcionários;

(7) Implantação/ Acessibilidade da Tecnologia da Informação.

(8) Certificações

\section{1) CAPACIDADE DE INOVAÇÃO}

REVISTA ECONOMIA POLÍTICA DO DESENVOLVIMENTO $\quad$ Maceió - AL $\quad$ V.4 N.6. $\quad$ DEZEMBRO/2017 P.80-99 Página-90


De acordo com os discursos dos gestores das empresas moveleiras integrantes do APL de Móveis de Arapiraca verificou-se que o APL Moveleiro do Agreste do Estado de Alagoas possui baixa capacidade de inovação, a partir das dimensões investigadas que foram (1) desenvolvimento de novos produtos/ design nos últimos 5 anos; (2) utilização de novas tecnologias de produção; (3) Utilização de Mão de Obra qualificada.

Considerando os casos de Implantação de Inovações implantadas, os gestoresrespondentes afirmaram que após cursos e estudos feitos sem a ajuda da APL, empresas implantaram inovações por contra própria, demonstrando assim interesse na inovação tecnológica. Uma das inovações implantadas que um dos entrevistados se referiu foi implantação de uma nova matéria prima utilizada na fabricação dos produtos, o MDF, que foi citado como a principal inovação implantada nos últimos 5 anos.

Considerando o aspecto desenvolvimento de novos produtos a pesquisa apontou certo comodismo dos gestores das firmas integrantes do APL de Móveis do Agreste de Alagoas ,os 15 respondentes que o APL Moveleiro do Agreste Alagoano até o momento em2016 eles se consideravam com baixa capacidade de inovação.

É importante registrar que a quase totalidade dos gestores entrevistados citaram como grande entrave para a institucionalização da inovação no território produtivo do APL moveleiro do Agreste do Estado de Alagoas, a baixa qualificação dos Recursos Humanos dos funcionários, sendo verificado que a imensa maioria dos marceneiros possuem apenas o ensino fundamental. Contudo, verificou-se que foram oferecidos cursos mediados pela empresa para os funcionários a fim de criar um maior grau de receptividade à inovação tecnológica: Em 70\% dos casos a APL ofereceu cursos com engenheiros e consultores voltados principalmente no melhor aproveitamento da matéria-prima, a responsabilidade com logística e capacitação de mão de obra. Uma pequena parte, cerca de 30\% das empresas integrantes do APL não demonstrou muito interesse nessa capacitação, porém, notou-se isso apenas na maioria das empresas do ramo de Serralheria. Faz-se necessário registrar o diferencial de inovação encontrado na empresa "Avinha Móveis". A loja assina revistas e todos os funcionários demonstram-se interessados em ampliar seu conhecimento praticando esses cursos a distância de maneira intensa.

Registra-se desta forma que os impactos decorrentes das poucas Inovações implementadas nos últimos 5 anos, especificamente em apenas 2 empresas no contexto das 15 que compuseram a amostra, foram os seguintes, de acordo com as entrevistas das 2 gestores das empresas do APL moveleiro que implantaram inovações: (1) Redução de custos do trabalho e enquadramento em normas padrão relativas ao mercado. A redução nos custos de trabalho foi evidenciada principalmente pelos cursos oferecidos pela APL por consultores do SEBRAE, além da modernização de equipamentos evitando assim o desperdício de matéria prima. (2) 
Aumento da produtividade da empresa e (3) Aumento na qualidade dos produtos. O aumento na produtividade da empresa foi evidenciada principalmente pela compra de novos equipamentos e na contenção de gastos, ampliando assim a produtividade e atingindo uma gama maior de clientes. Assim como na produtividade, inovações tecnológicas na parte mecânica aumentaram a qualidade dos produtos apresentados ao consumidor. Com isso, além do aumento da gama de clientes, tornou-se um fator de marketing na região.

\section{(2)FORMAS DE INTERAÇÃO ENTRE OS AGENTES LOCAIS}

A pesquisa realizada propiciou uma visão geral sobre as formas de interaçãoentre os agentes locais a partir da presença da Universidade do Estado de Alagoas (UFAL), através da recente expansão com a inauguração do Campi Arapiraca, da Universidade do Estado de Alagoas (UNEAL), UNEAL, CESMAC, bem como o Instituto Tecnológico (Instituto Federal, com o curso de Design). EstasInstituições poderiam contribuir efetivamente para facilitar um ambiente propício a geração de inovações e de aprendizado coletivo, uma ou outra pesquisa vem sendo realizada, mas ainda de forma muito tímida, a contribuição ainda não é de modo efetivo, nem sistemático, principalmente nos cursos de design, engenharia de produção que poderiam realizar uma parceria de forma mais efetiva.

Não foi visto laboratórios industriais de P\&D nas empresas visitadas no APL, nem existem pesquisas científicas realizadas pelas Universidadesna área de novas tecnologias/ produtos. Foi citada apenas uma pesquisa realizada pelo curso de Designdo Instituto Federal de Alagoas ( Maceió), em relação ao produção limpar, a respeito do mapeamento dos resíduos do condomínio Moveleiro do APL de Móveis do Agreste de Alagoas. Considerando as publicações científicase tecnológicas decorrentes da parceria entre Instituições de Ensino Superior e o APL Moveleiro do Agreste Alagoano, pode -se citar também a pesquisa sobre: “O impacto do pó de serra, barulho de motores e outros usos de materiais das indústrias de marcenarias no Agreste de Alagoas", desenvolvida pela FUNDACENTRO - Recife. Nenhuma pesquisa na área de design foi relatada entre os moveleiros entrevistados.

Considerando o grau de associativismo entre os gestores do APL, este fator está contribuindo em relação a facilitação da compra conjunta junto a fornecedores, pois tem apresentado bons resultados para as empresas do APL moveleiro do Agreste Alagoano. De acordo com os relatos por comprar insumos diretamente da fábrica, as empresas têm alcançado em média uma redução de $25 \%$ do preço em relação às aquisições em pequenos lotes de forma individual.

Contudo, todos os entrevistados ainda consideram incipientes o nível de interação entre os atores integrantes do APL moveleiro de Alagoas. Não menos importante para a geração de 
inovação é a articulação entre os atores dos Arranjos Produtivos e aspolíticas públicas específicas na área de ciência e tecnologia.

O interesse e a participação dos atores institucionais, como as Universidades na promoção da InovaçãonosAPL's pode contribuir para alargar esse enfoque para além de questões de competitividade, inovação e sustentabilidade econômica, tornando mais evidentes os nexos desses temas com questões como inclusão social, geração de emprego e renda, diminuição de desigualdades e respeito a diferenças regionais, distribuição da terra, desenvolvimento local, integração nacional e ocupação de fronteiras.

\section{(3) FONTES DE FINANCIAMENTO UTILIZADAS}

Na dimensão fontes de financiamento as entrevistas apontaram que o Arranjo Produtivo Local tem entre suas ações, promover a intermediação entre os empresários e as instituições financeiras, $1 / 3$ dos moveleiros entrevistados responderam que já conseguiram financiamento oriundo da Caixa Econômica Federal, Banco do Nordeste e do Banco do Brasil. Contudo, alguns entrevistados reclamaram da dificuldade de conseguirem um financiamento, considerando a situação de falta de comprovação de crédito da micro e pequena empresa.

\section{(4) MEIO DE TRANSPORTE UTILIZADO NA DISTRIBUIÇÃO DO PRODUTO}

Ao se considerar o meio de transporte utilizado para comercializar seus produtos as entrevistas apontaram que a maioria dos moveleiros $(75 \%)$ utilizam o transporte terceirizado, enquanto $25 \%$ responderam que possuem transporte próprio utilizado na distribuição dos produtos.

\section{(5) MAQUINÁRIO UTILIZADO E INOVAÇÃO TECNOLÓGICA IMPLANTADA NOS ÚLTIMO 5 ANOS}

Os Maquinários utilizados pelas empresas do arranjo estão em geral abaixo do nível de excelência, algumas empresas estão passando por uma mudança/ renovação do parque industrial, conforme a necessidade de atender melhor as exigências do mercado.

Ao se considerar a dimensão Inovação tecnológica, os gestores do APL moveleiro demonstraram conhecimento em relação as fontes de financiamento para a compra de novas máquinas que possam promover a inovação tecnológica, 4 entrevistados afirmaram que já conseguiram financiamento para compra de novos equipamentos, o que pode-se perceber a receptividade destes empresários em relação a inovação tecnológica, contudo esta é proporcional ao grau de instrução dos gestores. Porém em algumas empresas, notou-se que faltava maior interesse no referido assunto, principalmente onde os gestores/proprietáriospossuem um nível relativamente baixo de escolaridade/instrução, onde 
pode-se concluir que a falta de educação pode ser um entrave para o desenvolvimento das Inovações tecnológicas.

\section{(6) CAPACITAÇÃO DOS RECURSOS HUMANOS}

A rotatividade do trabalhador é muito grande, sendo os mesmos responsáveis por abrirem novos negócios no setor. O principal problema no mercado de trabalho é a baixa escolaridade, o alto grau de analfabetismo dos trabalhadores e a falta de Escolas Técnicas com cursos voltados para o segmento de marcenaria.

\section{(7) IMPLANTAÇÃO/ ACESSIBILIDADE DA TECNOLOGIA DA INFORMAÇÃO}

Sob o ponto de vista da percepção dos gestores do APL moveleiro em relação a implantação/ acessibilidade à tecnologia da Informação, os entrevistados afirmaram que houve um ganho a partir de 2015. Eles afirmaram que maior acessibilidade a tecnologia da informação proporcionou ganhos diretos. Considerando que os aspectos de (informatização das empresas, sistema de gerenciamento de estoque, máquinas de cartão de crédito, cursos à distância pela internet) foram os aspectos mais importantes da acessibilidade da tecnologia da Informação implantados em seus estabelecimentos. Foram verificadas em 10 empresas a compra de softwares, não podendo se caracterizar a implantação de inovação tecnológica em nenhuma empresa, que fizeram parte da amostra, participante do APL de móveis.

\section{(8) CERTIFICAÇÕES}

Considerando as empresas pesquisadas nenhuma delas possui certificações nacionais nem internacionais, nem em relação a proteção ambiental. As certificações e selos de qualidade ainda não foram desenvolvidas pelas empresas do APL, até fevereiro de 2016, nenhuma empresa havia sido certificada, com as certificações ISO 9000, ISO 14.000, entre outras.

\section{CONCLUSÃO:}

O objetivo desta pesquisa foi investigar a possibilidade de implantação de um ambiente propício a Inovações no Arranjo Produtivo de Móveis no Agreste do Estado de Alagoas, a partir do fortalecimento da interação entre os diversos atores.

Ao se analisar o tema da pesquisa inserido dentro da realidade histórico-social-cultural do Estado de Alagoas, um Estado carente que tem como característica uma forte concentração de renda e marcado por forte desigualdade social e grande parte da população predominantemente pobre, passa-se a perceber o grande desafio da Inovação, mais ainda de se Institucionalizar, ou 
seja, desenvolver um ambiente propício à disseminação de inovações. Em 2014 no quesito IDH, o Estado de Alagoas no Ranking entre os Estados da Federação ainda ocupa a posição de $26^{\circ}$. Lugar, ou seja, IDH de 0, 649, perdendo apenas para o Maranhão que é o último Estado da Federação, com o pior IDH do país, 0,636 . Ao se analisar os motivos porque a economia alagoana não se desenvolve de modo mais amplo, de acordo com Péricles (2015:8) este economista responde da seguinte forma: "A economia alagoana, hoje (2015), pode ser caracterizada como um conjunto produtivo marcado por três fortes ausências: a) falta-lhe um amplo mercado interno, decorrente de uma economia popular articulada que atenda à demanda regional, que aumente e distribua a renda, incorporando, dessa maneira, a maioria da população noprocesso de produção/ consumo; b) falta-lhe pólos dinâmicos capazes de substituir importações e realizar exportações (para o exterior e para outros estados), promovendo o crescimento regional e; c) falta-lhe um setor público (Estado e municípios) com capacidade de investimento.

A combinação desses três elementos explica tanto a frágilpresença de novas indústrias de móveis e as dificuldades na atração de empreendimentos produtivos ao longo de toda a Cadeia Produtiva de Móveis, pois o Estado de Alagoas obteve as menores taxas de crescimento econômico nos anos 90, que as da maioria dos estados nordestino, tendência que tem se repetindo na primeira década dos século XXI.O relativo estado de inércia na economia alagoana é explicado, por um lado, pela inexistência de um amplo mercado consumidor que tenha por de consumo e seja exigente por produtos de qualidade, bem como a inexistência de um empresariado numero e moderno capaz de realizar investimento, distribuídos espacialmente pelo território alagoano e geradores de dinâmica produtiva; por outro, a inércia é, também, justificada pela ausência de um Estado capaz de realizar os investimentos em infra-estrutura, independentemente das verbas federais; de dar contrapartida para atrair o capital de outras regiões em projetos de desenvolvimento, e oferecer um instrumento financeiro para as empresas que já estão instaladas e que carecem de recursos para sobrevivência ou ampliação.

Tentar entender como poderia se institucionalizar o processo de inovação no Arranjo Produtivo Local Moveleiro do Agreste de Alagoas sem uma estratégia que levasse em conta essas especificidades regionais, seria como uma estratégia fundamentada numa base "de vento", sem ser consolidada em solo firme. Pois, deve-se entender inicialmente o contexto históricosócio - cultural em que estas empresas que fazem parte do APL Moveleiro do Agreste Alagoano estão inseridas. Desta forma, para vencer seu atraso crônico, a economia alagoana precisa enfrentar estes três maiores problemas: ausência de um mercado interno, inexistência de pólos dinâmicos e em terceiro lugar as dificuldades financeiras do Estado.

As empresas que fazem parte do APL Moveleiro do Agreste Alagoano poderiam fazer um esforço coletivo e juntamente com a Secretaria do Estado de Ciência e Tecnologia e Universidades e Incubadoras propor a criação de pólos dinâmicos de inovação no setor moveleiro. \begin{tabular}{llllll}
\hline REVISTA ECONOMIA POLÍTICA DO DESENVOLVIMENTO & Maceió - AL & V.4 N.6. & DEZEMBRO/2017 & P.80-99 & Página-95
\end{tabular} 
Com relação a criação de um mercado interno, no caso específico do setor de móveis, existe na capital Maceió/Al, um grande número de empresas do Rio Grande do Sul que atendem uma parcela significativa da população da capital alagoana, bem como das cidades vizinhas. Fica uma pergunta no ar: Porque os Maceioenses não compram móveis de Arapiraca ou de Palmeira dos Índios? Vamos por parte, as franquias de móveis do Rio Grande do Sul que estão presentes na Capital Maceió atendem clientes da classe social A e B e estão presentes nos bairros situados na orla marítima da cidade, considerada área nobre. Os consumidores que residem nestes bairros de Maceió: Ponta Verde, Pajuçara, Jatiúca, Cruz das Almas, Jaraguá e consomem os móveis sob medida das lojas do Rio Grande do Sul, buscam dois aspectos: (1) qualidade; (2) confiança na marca; (3) profissionalismo.

É importante registrar que uma loja do APL Moveleiro do Agreste do Estado de Alagoas abriu um ponto de venda em Maceió, esta loja possui um Show room próprio, com móveis diferenciados e percebe-se uma estratégia agressiva de penetração junto a alguns nichos de mercado.

Verificou-se que a economia alagoana tem apresentado historicamente, ao longo de décadas dificuldade em se desenvolver e este fator impacta na frágil presença de novas indústrias e as dificuldades de atração de empreendimentos produtivos ao longo da Cadeia Produtiva de Móveis. O relativo estado de inércia na economia, pode ser explicado pela inexistência de um empresariado numeroso e moderno capaz de realizar investimentos distribuídos espacialmente pelo território alagoano e geradores de dinâmica produtiva. Estes fatos também impactam diretamente na dificuldade de se promover uma estratégia de inovação tecnológica, pois demandaria fortes investimentos. A inércia, também é justificada pela ausência de um Estado capaz de realizar os investimentos em infraestrutura, independentemente das verbas federais.

Sendo assim, ainda pode se questionar: Como poderia se promover o processo de Inovação no APL Moveleiro do Agreste do Estado de Alagoas?

De acordo com Cassiolato e Lastres (2010) estes avaliam fatores como o ambiente, história e tecnologia, investigando como a definição de padrões assume a condição de valores e adquirem legitimidade nas estruturas sociais. Scott (2005: 6) revela um conjunto de características que são: preocupação com estruturas formais e sistemas legais, abordagem com relatos detalhados de sistemas particularmente políticos, reconstrução histórica de formas institucionais específicas. Para se refletir sobre como se poderia se institucionalizar o processo de Inovação no APL Moveleiro do Agreste do Estado de Alagoas, teria que se partir de uma discussão complexa que envolveria algumas dimensões: (1) Aumento do Nível de Escolaridade dos gestores/Proprietários/Funcionários; (2) Capacitação Técnica; (3) Apoio/Parceria Sistemática e Efetiva das Instituições de Pesquisa (Universidades); (4) Parcerias com outros 
Arranjos Produtivos de Móveis para transferência de tecnologia, a exemplo do APL de Móveis do Rio Grande do Sul e de Ubá/MG;(5) Parcerias com Fornecedores ao longo de toda a Cadeia Produtiva de Móveis. (6) Esforço concentrado em Design, produtividade, qualidade do produto; (7) Profissionalismo; (8) Desenvolvimento de Marca. Enfim, o esforço para consolidação do Arranjo Produtivo de Móveis do Agreste Alagoano é um trabalho árduo que deve ser iniciado. Esta pesquisa identificou que o APL Moveleiro do Agreste do Estado de Alagoas ainda está se consolidando, pois apesquisa detectou ainda o baixo nível de interação e envolvimento dos empresários que compõem o APL.Um dos aspectos interessantes na discussão sobre a participação dos diversos atores, que emerge no bojo da iniciativa de integração de ações é a articulação dos atores, até então ausentes de um possível fórum dessa natureza.

As interações podem ser de natureza cooperativa e/ ou competitiva, estendem-se além do relacionamento comercial e tendem a gerar, afora os ganhos de escala, economias externas, associadas à socialização do conhecimento e à redução dos custos de transação. No APL de Móveis do Agreste Alagoano, as unidades produtivas poderiam ter atividades similares e/ou complementares, em que predomina a divisão do trabalho entre os seus diferentes participantes - empresas produtoras de bens e serviços, centros de pesquisa, centros de capacitação e treinamento e unidades de pesquisa e desenvolvimento, públicas e privadas.

No caso dos Arranjos Produtivos Locais de móveis no Agreste Alagoano o programa se depara com empresário habituado que ver o outro empresário sempre como seu concorrente, ignorando a importância de qualquer forma de cooperação ou diálogo que dificulta a cooperação, a interação e consequentemente a promoção conjunta de inovações de produtos nas firmas fica prejudicada.

Essa cultura de um integrante do APL de móveis no Agreste Alagoano ver a outra firma como concorrente é contrária ao pressuposto dos princípios em que o APL se fundamenta que num APL as firmas integrantes possam se ajudar, trocar conhecimento, cooperar para competir e buscar conjuntamente objetivos mútuos. Portanto as empresas de um APL que possuem um alto grau de interação e cooperação podem desenvolver novas tecnologias, entrar em novos mercados e / ou reduzir custos de fabricação. A cooperação entre as firmas de um APL muitas vezes é o meio mais rápido e eficiente de atingir objetivos e podem ser importantes não apenas pelo acordo imediato, mas também porque criam oportunidades adicionais e não previstas que abrem portas para o futuro.

Desta forma pode se caminhar na direção de uma busca de maior competitidade do APL de Móveis do Agreste Alagoano com foco na forma de fazer negócios, que inclua todas as possíveis cooperações e competições, provê uma base muito mais clara para se aproveitar as oportunidades que essas novas e complexas situações oferecem. Pois, a interação entre os 
atores das firmas integrantes de um APLexigem que os parceiros contribuam com uma parte dos seus conhecimentos técnicos ou empresariais. Essa transferência de conhecimentos poderá ser uma fonte valiosa de ideias inovadoras.

A principal característica da interação entre firmas é a construção de um relacionamento contínuo, em vez de uma série de transações isoladas. A confiança é gerada à medida que as partes se concentram na satisfação do cliente e na lealdade, estimulando esforços cooperativos de vendas, intercâmbio de informações tecnológicas ou mercadológicas, com o compartilhamento de recursos e conhecimentos para aumentar a competitividade. Portanto há necessidade de se promover e estimula uma maior interação entre os atores que integram o dos Arranjos Produtivos Locais de móveis no Agreste Alagoano, interações baseadas no associativismo entre as empresas de pequeno porte deste APL, pois a inovação é uma atividade de cooperação que emerge da integração de múltiplas perspectivas, por outro, a inovação é fundamentalmente um produto do conhecimento e da criatividade.

\section{REFERÊNCIAS}

ANSOFF, Igor; McDONNELL, E. J. Implantando a administração estratégica.2.ed. São Paulo, Atlas, 2003.

BIDAULT, Francis; CUMMINGS, Thomas. Os benefícios ocultos das alianças. Jornal Gazeta Mercantil. São Paulo: Caderno Especial: O Domínio da Administração. n 19. 02 janeiro 1999, p. 13-15.

BUZZEL, R. D.; GALE, B. T.The PIMS principles: linking strategy to performance. New York: Free Press, 1987

CASSIOLATO, José E.; LASTRES, Helena M. (organizadores).Estratégias para o desenvolvimento: um enfoque sobre Arranjos Produtivos Locais do Norte, Nordeste e Centro - Oeste brasileiros. Rio de Janeiro: E-papers, 2015.

CAPORALI; VOLKER, Paulo. Metodologia de desenvolvimento de arranjos produtivos locais. Projeto Promos - Sebrae - BID. Brasília: sebrae, 2004.

DAY, George S. Estratégia Voltada para o Mercado: Processos para a criaçãode valor dirigidos ao cliente. Rio de Janeiro: Record, 1990.

DRUCKER, Peter. Administrando para o Futuro: os anos 90 e a virada doséculo. $6^{\text {a }}$ ed. São Paulo: Pioneira, 1996.

FAHEY, Liam. Competitors: outwitting, outmaneuvering and outperforming. New York: Wiley, 1999.

GALBRAITH, Jay R.; LAWLER III. Organizando para competir no futuro: estratégia para gerenciar o futuro das organizações.São Paulo, Makron, 2005.

GRANT, Robert M. Contemporary strategy analysis.3.ed. Malden, Blackwell, 2008.

HAN, Jin K; KIM, Namwoon; e SRIVASTAVA, Rajaendra. Market Orientation and Organizational Performance:Is Innovation a Missing Link? Jounal of Marketing, October, 2008.

HURLEY, Robert F; HULT, G. Thomas M. Innovation, Market Orientation, and OrganzationalLearning:An Integration and Empirical Examination. Journalof Marketing, v 62, July, 1998, p. 42-54.

KUCZMARSKI, Thomas D. Por uma Consciência Inovadora. Revista HSM Management. São Paulo: Janeiro- fevereiro, 1998, p $16-20$

LASTRES, H.M.M; CASSIOLATO, J.E \& ARRIO. A. (Org). Conhecimento, Sistemas de Inovação e Desenvolvimento. Rio de Janeiro. Editora UFRJ/ Contrponto, 2005. 
MINTZBERG, Henry. The innovativeorganization.In: MINTZBERG, Henry; QUINN, James Brian (Eds.). Readings in the strategy process.3.ed.New Jersey, Prentice-Hall, 1998a.p.309-323.

NONAKA, Ikujiro; TAKEUCHI, Hirotaka. Criação de conhecimento na empresa: como as empresas japonesas geram a dinâmica da inovação. Rio de Janeiro: Campus, 1998.

PRAHALAD, C. K.; HAMEL, Gary.The core competence of the corporation. May/Jun. 1990. In: MONTGOMERY, Cynthia A.; PORTER, Michael (Eds.). Strategy: seeking and securing competitive advantage. Boston, HBS Press, 2001. p.277-299.

PETROCHI, M. Programa de Mobilização para o Desenvolvimento dos APL's do Estado de Alagoas. SEBRAE/ AL, 2015.

PORTER, Michael. Clusters and competition.1998 In: PORTER, Michael. On competition. Boston: HBS Press, 1998. p. 197-287.

QUINN, James Brian. Managing innovation: controlled chaos. May/June 1985. In: MINTZBERG, Henry; QUINN, James Brian (Eds.). Readings in the Strategy Process.3.ed. New Jersey: Prentice-Hall, 2008.

QUEIROZ, Ana Carolina S. Inovação Organizacional e Tecnológica. São Paulo: Thomson Learning, 2007.

ROBERT, Michael. A Estratégia pura e simples da Inovação do produto: como o processo de inovação pode ajudar a sua empresa a suplantar os concorrentes. Rio de janeiro: Nórdica, 2005.

SEBRAE.

Arranjos

Produtivos

Locais.

http://www.redeaplmineral.org.br/biblioteca/cartilhas/Fasciculo\%20APL\%20-\%20Sebrae.pdf. Acesso em $11 / 10 / 16$ 